\title{
The FDA De Novo medical device pathway, patents and anticompetition
}

\author{
The interaction between patents and FDA's De Novo and $510(\mathrm{k})$ regulatory pathways has the potential to threaten \\ follow-on innovation for medical devices.
}

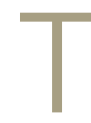

he US Food and Drug Administration (FDA) has long been criticized perhaps unfairly - for failing to expeditiously approve groundbreaking medical devices. In the views of some, this has contributed to stagnation in the advancement of the medical device market and depressed competition among purveyors of new devices. The 21st Century Cures Act of 2016 has been lauded for attempting to tackle these problems by easing several pathways for regulatory allowance. But some of the agency's recent guidances in the area may hinder competition by opening the gates to an anticompetitive patent strategy, one whereby marketers of De Novo medical devices - medical devices given their own 'device type' category - can kettle follow-on applicants into patent infringement litigation. Knowing this, marketers of medical devices may avoid the 21st Century Cures Act's expansion of the $510(\mathrm{k})$ pathway for De Novo device types, defeating one of the principal purposes of the act.

\section{The FDA De Novo pathway}

This anticompetitive patent strategy begins with how the 21st Century Cures Act governs De Novo medical devices. De Novo devices are those for which general and special "controls" provide a "reasonable assurance" of the device's safety and effectiveness, even though there are no legally marketed devices of the same type ${ }^{1}$. These controls are basic requirements to ensure devices' safety and efficacy in the real-world marketplace (for example, requirements pertaining to manufacturing practices) or, in the case of special controls, specific to the device type, such as performance standards; for instance, that external cardiac pacemakers should not deliver current at a pulse amplitude greater than $200 \mathrm{~mA}$.

In general, special controls for De Novo devices present a problem to FDA because the requirements to ensure "safety and effectiveness" are difficult to know without extensive testing in the field. In one case, topical tissue adhesives - 'liquid bandages' - were found to need special controls a full decade after they were first introduced ${ }^{2}$.
Those controls related to the heat degradation properties of such bandages; unexpectedly, heat from the skin degraded one component of the gel into formaldehyde. Because De Novo devices are, as the name suggests, new device types, problems such as these present the quandary of how to ascertain, with minimal historical comparisons, which special controls would be needed to ensure their safety and effectiveness.

In an attempt to cut this epistemic knot, FDA has recently finalized a regulatory guidance that asks De Novo applicants to propose for themselves their devices' respective special controls ${ }^{3}$. Such proposals must come with explanations for why such controls "provide a reasonable assurance of safety and effectiveness" and can include a wide variety of factors, including those related to devices' usability, biocompatibility, and stability over time. In addition, these special controls (some of which are also classified as "performance standards") may cover a device type's core "technological characteristics," its "materials, design, energy source, and other device features"

These controls are critical for the $510(\mathrm{k})$ pathway - the pathway by which over $96 \%$ of new devices are reviewed by the agency ${ }^{5}$. The interest in the $510(\mathrm{k})$ pathway stems from its leniency: rather than mandating clinical trials, $510(\mathrm{k})$ devices are cleared by FDA, typically within 90 days, if their manufacturers can show "substantial equivalence" to a "predicate device." This determination requires a number of steps, but two are of importance here. A $510(\mathrm{k})$ device must endeavor to show that it possesses the same "technological characteristics" as the predicate device. If it fails to do so, the applicant must then instead show that the follow-on device does not raise any "different questions of safety and effectiveness" . Failing this, the device is "not substantially equivalent" to the predicate and therefore cannot be marketed ${ }^{6}$.

\section{Patents covering De Novo devices' technological characteristics and controls}

The combination of these guidances and the 21st Century Cures Act establishes a potentially anticompetitive patent strategy. De Novo applicants may patent the core technological characteristics of their devices, essential for FDA's determination that the follow-on application is "substantially equivalent." In addition, the De Novo applicant can advocate before the agency that its "performance standards" are, in fact, core technological characteristics for the device's "special controls." As a result, a follow-on applicant is given a fatal choice: it must either admit that it uses the same technological characteristics as the patented, predicate device - essentially, an admission of patent infringement - or that it uses different technological characteristics, which is an admission that the device is not substantially equivalent to the predicate. In short: patenting core technological characteristics of a De Novo device and tying performance standards to these underlying technological characteristics gives follow-on developers an impossible path toward entry.

While this anticompetitive strategy is a nascent worry, it is decidedly real. Take, for example, the t:slim X2 Insulin Pump, marketed by Tandem Diabetes Care, classified as a De Novo device in 2019 (ref. ${ }^{7}$ ). Its special controls include "[e]lectrical safety, electromagnetic compatibility, and radio frequency wireless safety testing," including the "[s]haring of necessary state information between the pump and any digitally connected alternate controllers" - controls that overlap the device's core technological characteristics. But these very characteristics have been patented by Tandem Diabetes Care ${ }^{8}$. A potential 510(k) application using the t:slim X2 Insulin Pump as a predicate would therefore be faced with either admitting to the FDA that it either uses the same technological characteristics as the pump, and likely infringes Tandem's patents, or that it fails to match the pump's performance standards - an admission that its $510(\mathrm{k})$ should not be approved.

The Bose Hearing Aid presents another example of patents covering De Novo devices' special controls. The hearing aid - specifically typed as a "self-fitting 
air-conduction hearing aid" - uses active noise reduction technology, a feature designed to "reduce environmental noise and to decrease amplification of the user's own voice typical of an occluding earbud". This includes directional sensitivity, the ability of the hearing aids' microphones to detect the presence of louder-than-room sound in only one ear's hearing aid. This makes the Bose Hearing Aid's directional sensitivity a core feature of the device's "electroacoustic parameters," one of its special controls. But this directional sensitivity is precisely what is claimed in Bose's US Patent 10,623,870, making follow-on applicants interested in making their own active noise reduction hearing aid targets for claims of patent infringement. This is potentially concerning given the quantity of patent litigation clouding the hearing aid market ${ }^{10-12}$.

NeuroSigma's transcutaneous electrical nerve stimulator for attention deficit hyperactivity disorder, the Monarch eTNS System, similarly lists specific electrical stimulation parameters as special controls ${ }^{13}$. But the company has at least ten patents covering various aspects of its De Novo device, including US Patent 10,195,435, which claims the same ranges of frequency, pulse duration, output current density and charge density as the Monarch eTNS. Any 510(k) applicants seeking to use these same parameters for their own ADHD stimulators - as they would be required under FDA's recent guidances - would make themselves ripe for claims of patent infringement.

Examples such as these are likely to become commonplace. In the three years since the act was signed into law, FDA has approved 97 De Novo devices - roughly 30 a year - in contrast to an average of about 9 devices in years prior. In addition, many medical devices are becoming increasingly complex such that controls on elements like energy sources and software - core technological characteristics - are the difference between devices being safe and effective and them being dangerous contraptions ${ }^{14}$. These developments are likely to increase an already high baseline level of patent litigation for medical devices $-6 \%$ of the roughly 4,500 patent cases filed each year, more than cases pertaining to telecommunications, chemicals or cars ${ }^{15}$.

In addition, the relationship between devices' special controls and patents covering them has the potential to affect diagnostic testing for diseases, such as COVID-19. Because many diagnostic tests are legally considered to be medical devices in FDA's purview, one of the more popular avenues for approval for diagnostic tests is the De Novo pathway. Indeed, approved
De Novo devices already include test kits for Zika ${ }^{16}$, Ebola $^{17}$ and West Nile ${ }^{18}$ viruses, among others. Unsurprisingly, such kits are subject to robust special and performance controls to ensure their clinical and analytic validity, controls that can rarely be sidestepped by follow-on applicants. If the providers of such devices patent these controls, $510(\mathrm{k})$ applicants would be effectively blocked from offering competing devices. While this is currently less of a concern for COVID-19 test kits because of the way in which they have been authorized by FDA - under an Emergency Use Authorization pathway, with less stringent controls - patents covering the kits' special controls may well take an anticompetitive bent once the pandemic begins to subside and the agency starts to require preapproval applications such as those from the De Novo pathway.

\section{Conclusions}

The interaction between patents and FDA's De Novo FDA 501(k) pathways present an opportunity for regulatory gamesmanship that potentially detracts from a history of robust development in the medical device space. Unlike approval of drugs, regulatory approval of medical devices is not tied to a prior resolution of patent infringement. This has, since the Medical Device Amendments of 1976, allowed the robust and competitive development of the medical device market, including the opportunity to garner real-world evidence of devices' safety and effectiveness; follow-on applicants could negotiate for patent licenses after approval. And while the $510(\mathrm{k})$ pathway has come under some recent criticism ${ }^{19}$, the fact remains that the vast bulk of medical devices in the United States enter the market this way. The medical device market largely turns on how the $510(\mathrm{k})$ process is governed.

FDA's guidances on special controls are an admirable step in the right direction. But the agency should be aware of how De Novo applicants establishing their own controls where applicants' interests may be aligned to thwart competition - are problematic. Foxes tend not to be good stewards of henhouses. FDA should clarify its guidances to note that it will review - and vigorously so - whether De Novo applicants' specific special controls employed are necessary for the device's safety and efficacy and whether they overlap with the core technological characteristics of the device itself. FDA could also ask De Novo applicants whether any proposed, novel special controls could be otherwise satisfied using industry standards, which tend to be less prone to patent blocking. And, in general, better oversight of performance standards for De Novo devices from FDA is needed. Policing such behavior would ensure that the 21st Century Cures Act continues the advance of competition in the medical device marketplace.

\section{Jacob S. Sherkow (D) 1,2,3凶 and Mateo Aboy $4,5 \bowtie$}

${ }^{1}$ College of Law, University of Illinois at Urbana-Champaign, Champaign, IL, USA. ${ }^{2} \mathrm{Carl}$ R. Woese Institute for Genomic Biology, University of Illinois at Urbana-Champaign, Champaign, $I L$, USA. ${ }^{3}$ Center for Advanced Studies in Biomedical Innovation Law, University of Copenhagen Faculty of Law, Copenhagen, Denmark. ${ }^{4}$ Centre for Law Medicine and Life Sciences, University of Cambridge, Cambridge, UK. ${ }^{5}$ Petrie-Flom Center for Health Law Policy, Biotechnology, and Bioethics, Harvard Law School, Cambridge, MA, USA.

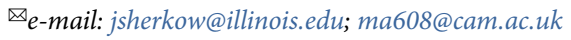

Published online: 4 September 2020 https://doi.org/10.1038/s41587-020-0653-6

References

1. 21st Century Cures Act. Public Law No 114-255 (2016)

2. FDA. Guidance for industry and FDA staff: class II special controls guidance document: tissue adhesive for the topical approximation of skin. https://www.fda.gov/media/71148/ download (2008).

3. FDA. Acceptance review for de novo classification requests: guidance for industry and Food and Drug Administration staff. https://www.fda.gov/media/116945/download (2019).

4. 21 U.S.C.A. $\$ 360 \mathrm{c}(\mathrm{i})(1)$

5. FDA. FY 2018 Performance report to Congress for the Medical Device User Fee Amendments. https://www.fda.gov/ media/130598/download (2019).

6. FDA. The $510(\mathrm{k})$ program: evaluating substantial equivalence in premarket notifications. https://www.fda.gov/media/82395/ download (2014).

7. Kelm, K. B. Letter from Kellie B. Kelm, Acting Director, Division of Chemistry and Toxicology Devices, FDA, to Michael Sarrasin, Senior Director of Regulatory and Clinical Affairs, Tandem Diabetes Care, Inc. https://www.accessdata.fda.gov/cdrh_docs/ pdf18/DEN180058.pdf (3 December 2019).

8. Kruse, G. US Patent 10,492,141 (2019).

9. FDA. De Novo classification request for Bose $e^{\bullet}$ Hearing Aid: decision summary. https://www.accessdata.fda.gov/cdrh_docs/ reviews/DEN180026.pdf (2018).

10. Energy Transp. Group, Inc. v. William Demant Holding A/S, 697 F.3d 1342 (Fed. Cir. 2012).

11. Hearing Components, Inc. v. Shure Inc., 600 F.3d 1357 (Fed. Cir. 2010).

12. Manchester v. Sivantos GmbH, Case No. 2:17-CV-05309 (C.D. Cal. 2 August 2019).

13. FDA. De Novo classification request for Monarch eTNS System: decision summary. https://www.accessdata.fda.gov/cdrh_docs/ reviews/DEN180041.pdf (2019).

14. Minssen, T., Gerke, S., Aboy, M., Price, N. \& Cohen, G. J. Law Biosci. https://doi.org/10.1093/jlb/lsaa002 (2020).

15. PwC. 2018 patent litigation study. https://www.pwc. $\mathrm{com} / \mathrm{us} / \mathrm{en} /$ forensic-services/publications/assets/20 18-pwc-patent-litigation-study.pdf (2018).

16. FDA. Evaluation of automatic class III designation for ZIKV Detect 2.0 IgM Capture ELISA: decision summary. https://www. accessdata.fda.gov/cdrh_docs/reviews/DEN180069.pdf (2019).

17. Evaluation of automatic class III designation for OraQuick Ebola Rapid Antigen Test: decision summary. https://www.accessdata. fda.gov/cdrh_docs/reviews/DEN190025.pdf (2019).

18. Gutman, S. I. Letter from Steven I. Gutman, Director, Office of In Vitro Diagnostic Device Evaluation and Safety, FDA, to Kate Wersin, Regulatory Affairs Officer, PANBIO Limited. https:// www.accessdata.fda.gov/cdrh_docs/pdf3/K031703.pdf (8 July 2003).

19. Rathi, V. K. \& Ross, J. S. N. Engl. J. Med. 381, 1891-1893 (2019).

Competing interests

M.A. serves on the board of APDM Wearable Technologies (APDM, Inc). 